\title{
Population-level effects of egg predation on a native planktivore in a large freshwater lake
}

\author{
David B. Bunnell ${ }^{1}$, Justin G. Mychek-Londer ${ }^{2 *}$, Charles P. Madenjian ${ }^{1}$ \\ ${ }^{1}$ USGS Great Lakes Science Center, 1451 Green Rd, Ann Arbor, MI 48105, USA \\ ${ }^{2}$ School of Natural Resources and Environment, University of Michigan, Dana Building, 440 Church Street, Ann Arbor, MI 48109, USA \\ *Present address: Great Lakes Institute for Environmental Research, University of Windsor, 401 Sunset Avenue, Windsor, Ontario N9B 3P4, Canada
}

Accepted for publication October 18, 2013

Abstract - Using a 37-year recruitment time series, we uncovered a field pattern revealing a strong, inverse relationship between bloater Coregonus hoyi recruitment success and slimy sculpin Cottus cognatus biomass in Lake Michigan (United States), one of the largest freshwater lakes of the world. Given that slimy sculpins (and deepwater sculpin Myoxocephalus thompsonii) are known egg predators that spatiotemporally overlap with incubating bloater eggs, we used recently published data on sculpin diets and daily ration to model annual bloater egg consumption by sculpins for the 1973-2010 year-classes. Although several strong year-classes were produced in the late 1980s when the proportion of eggs consumed by slimy sculpins was extremely low (i.e., $<0.001$ ) and several weak year-classes were produced when the proportion of bloater eggs consumed was at its highest (i.e., $>0.10-1.0$ ), egg predation failed to explain why recruitment was weak for the 1995-2005 year-classes when the proportion consumed was also low (i.e., $<0.02$ ). We concluded that egg predation by slimy and deepwater sculpins could have limited bloater recruitment in some years, but that some undetermined factor was more important in many other years. Given that slimy sculpin densities are influenced by piscivorous lake trout Salvelinus namaycush, the restoration of which in Lake Michigan has lagged behind those in lakes Superior and Huron, our study highlights the importance of an ecosystem perspective when considering population dynamics of fishes.

Key words: recruitment; lake trout; ecosystem management; deepwater cisco; Great Lakes

\section{Introduction}

Understanding recruitment variability is a high priority for fishery managers and scientists given the disproportionate impact that recruitment can have on fisheries production (Houde 1987; Myers \& Barrowman 1996; Walters \& Martell 2004). Although spawning stock size (best characterised as population egg production) must play some role in shaping recruitment, nearly a century of research has demonstrated that additional factors underlie recruitment variation. For example, the importance of overlap between first-feeding larvae and their prey (Hjort 1914; Cushing 1968), the role of predation on early life stages (Mills et al. 1987; Leggett \& DeBlois 1994; Mason \& Brandt 1996; Riley \& Marsden 2009), as well as the impact of climatic variables (Leggett et al. 1984; Brown et al. 1993; Hurst 2007) each has explained recruitment variability in fish pop- ulations. Incorporating these variables into models that traditionally were based only on spawning stock size also is consistent with the move towards ecosystem-based fishery management.

Bloater Coregonus hoyi is a freshwater fish endemic to four of five Laurentian Great Lakes. As an adult, it occupies the offshore, hypolimnetic waters and undergoes diel vertical migrations within this habitat to feed upon benthic macroinvertebrates and zooplankton (TeWinkel \& Fleischer 1999). It spawns in this cold environment between January and March, and its eggs incubate for up to 4 months (Rice et al. 1987b). Up to the 4th week of life, larvae remain benthic; then, larvae undergo an ontogenetic shift to the warmer pelagic waters for up to their first year or two (Crowder \& Crawford 1984; Rice et al. 1987b) before shifting back to the hypolimnion as an adult. In the three lakes where it remains extant (Superior, Michigan and Huron), bloater has exhibited a synchronous 
Table 1. Factors that have been hypothesised to influence recruitment of bloater in Lake Michigan

\begin{tabular}{ll}
\hline & References \\
\hline Female predominance: Too few males & Brown et al. (1987); \\
cause females to not spawn or limit & Bunnell et al. (2006) \\
fertilisation of eggs that are spawned. & \\
Condition-dependent fecundity: Reduced & Bunnell et al. (2009) \\
condition of adults has reduced & \\
size-dependent fecundity. & Rice et al. (1987b); \\
Climate: Cold winters could prolong egg & Bunnell et al. (2010) \\
incubation period and increase & \\
vulnerability of eggs to predators. & Rice et al. (1987a,b) \\
Starvation of first-feeding larvae: Too few & \\
zooplankton available to feed upon after & \\
yolk-sac absorption is complete; & \\
starvation could also increase vulnerability & \\
to predation. & Wells \& Beeton (1963); \\
Cannibalism: Bloaters increase egg & Rice et al. (1987a) \\
predation as spawning stock size & \\
increases and also can consume their own & \\
larvae in the laboratory. & Wells (1980); Rice \\
Egg predation by other species: Slimy & et al. (1987b); \\
sculpin and deepwater sculpin consume & Mychek-Londer et al. \\
bloater eggs. & (2013) \\
& Stedman \& Argyle \\
Predation on larvae and juvenile age-0 & (1985); Rice et al. \\
bloater by other species: Nonindigenous & (1987a,b); Eck \\
adult alewife and rainbow smelt consume & \& Wells (1987); \\
bloater up to 76 mm total length. & Madenjian et al. \\
& (2008) \\
\hline & \\
\hline & \\
& \\
&
\end{tabular}

recruitment pattern (Bunnell et al. 2010) that is somewhat unusual among fish populations. Unlike most populations that exhibit strong interannual variability, bloater populations undergo 10-15 years of relatively strong recruitment followed by 10-15 years of relatively weak recruitment (Bunnell et al. 2006).

Several explanations for this pattern have been proposed (Table 1), and although some have been evaluated, the key underlying mechanisms remain poorly understood. Conventional stock/recruitment models cannot be applied to the Lake Michigan bloater population given its nonstationary recruitment pattern (i.e., the relationship between population egg production and recruitment varies with time; see Walters 1987). In essence, similar numbers of eggs were produced in the mid-1980s and late 1990s, yet recruitment was two orders of magnitude higher in the mid-1980s (Bunnell et al. 2006). Even accounting for changes in size-specific fecundity over these years failed to remove the nonstationary pattern (Bunnell et al. 2009). Time series models that accounted for nonstationarity revealed adult sex ratio to be the strongest predictor of recruitment in both Lake Michigan (Bunnell et al. 2006) and Lake Huron (Collingsworth et al. in press): years with a higher proportion of females (could exceed 90\% in some years) among all adults tended to produce weaker year-classes. Nonetheless, the mechanism by which an excessive num- ber of females (or a relatively low number of males) could limit recruitment success has yet to be elucidated, in part, because of the lack of knowledge of bloater-spawning behaviour.

Starvation of first-feeding larvae could be hypothesised given the shifts in zooplankton community composition that have occurred during the past decades, including declines in small cladoceran zooplankton (Barbiero \& Tuchman 2004; Barbiero et al. 2012) that can be an important prey for first-feeding larvae. Yet, bloater hatch at relatively large sizes $(\sim 10 \mathrm{~mm}$, Auer 1982), which should confer reduced risk of starvation (Miller et al. 1988). Furthermore, laboratory studies have revealed that $50 \%$ of bloater larvae can survive without food for up to 25 days after hatch (Rice et al. 1987a). Finally, the recruitment synchrony that was observed across lakes Superior, Michigan and Huron suggests that some broad regional climate variable could be driving the long-term recruitment variability (Bunnell et al. 2010). Yet no regional climate index (e.g., Pacific Decadal Oscillation, El Niño-Southern Oscillation and Arctic Oscillation) was synchronised with the regional bloater recruitment pattern (D. B. Bunnell, unpublished data), and time series analyses within lakes Michigan and Huron revealed minimal explanatory power of climate variables (Bunnell et al. 2006; Collingsworth et al. in press).

Herein, we sought to evaluate the hypothesis that predation on early life history stages could be regulating bloater recruitment variability in Lake Michigan, with the assumption that if it were found to be important in this lake, then it might also be important in lakes Huron and Superior. In theory, predation could regulate bloater recruitment under three different scenarios. First, nonindigenous adult alewives $A l$ osa pseudoharengus are effective predators of fish larvae (Hoagman 1974; Rice et al. 1987a; Krueger et al. 1995), and when bloater recruitment in the late 1970s began increasing while alewife densities declined, some hypothesised that predation by adult alewife on bloater larvae had been a recruitment bottleneck (e.g., Eck \& Wells 1987). More recent studies, however, have discounted this hypothesis given the limited spatiotemporal overlap between adult alewife and pelagic bloater larvae (Madenjian et al. 2008) and the lack of explanatory power of adult alewife in bloater recruitment models (Bunnell et al. 2006). Juvenile and even adult bloater also can comprise relatively small proportions of the diets of rainbow smelt Osmerus mordax (Stedman \& Argyle 1985), lake trout (Madenjian et al. 1998) and even burbot Lota lota (Fratt et al. 1997), yet these are not believed to be sufficiently high to negatively affect their population dynamics. The second and third scenarios involve predation on incubating bloater eggs or even benthic yolk-sac larvae. Cannibalism could 


\section{Bunnell et al.}

be occurring given that fish eggs (though not confirmed as bloater) were observed in bloater diets during April (Wells \& Beeton 1963). Although cannibalism could explain poor recruitment at high spawning stock sizes, it fails to account for the nonstationary recruitment pattern (i.e., under similar levels of egg production, why would cannibalism be high during some periods and low during others). Additionally, native slimy sculpin Cottus cognatus and deepwater sculpin Myoxocephalus thompsonii are known to consume fish eggs during March and April (Wells 1980), and a companion study to ours confirmed that bloater were included among the species of eggs consumed by sculpins in 2009-2010 (Mychek-Londer et al. 2013).

In this article, we evaluated the hypothesis that egg predation by slimy and deepwater sculpin regulated the recruitment of bloater in Lake Michigan between 1973 and 2009. First, we used a long-term data set to demonstrate that bloater recruitment to age 3 was inversely related to the biomass of slimy, but not deepwater, sculpin. Second, to determine whether this relationship was causal, we developed models to predict annual consumption of bloater eggs by slimy sculpin dating back to 1973 and compared the proportion of bloater eggs consumed with corresponding bloater recruitment three years later. Although no field relationship was uncovered between deepwater sculpin and bloater recruitment, we also modelled consumption by deepwater sculpin given that both deepwater and slimy sculpin were found to consume bloater eggs during February through May, 20092010 (Mychek-Londer et al. 2013).

\section{Methods}

\section{Relationship between bloater recruitment and sculpin} biomass

Biomass and abundance of bloater, slimy sculpin and deepwater sculpin were derived from a U.S. Geological Survey (USGS) bottom trawl study that has annually sampled up to 11 depths (ranging from 9 to $110 \mathrm{~m}$ in approximately $10-\mathrm{m}$ strata) at seven sites during the day in Lake Michigan in the fall since 1973 (for additional details see Bunnell et al. 2006). At each depth and site combination, a 12-m Yankee bottom trawl was fished for up to $10 \mathrm{~min}$. Area swept (in ha, width of the net multiplied by actual time on bottom) was estimated as a function of fishing depth $(D$, in $\mathrm{m})$ and tow time (TT, in min) according to the following equation (Bunnell et al. 2013): width of the net $=3.232+7.678$ $\left(1-e^{-0.044 \times D}\right)$; actual time on bottom $=$ TT $-0.945+(0.056 \times D)$. The catch from each haul was sorted to species, weighed to the nearest $g$, and up to 100 individuals were randomly selected for the measurement of total length (TL) to the nearest $\mathrm{mm}$. When catches exceeded $20 \mathrm{~kg}$, the total catch was weighed and a random subsample was processed as previously described and extrapolated by direct proportion.

To index bloater recruitment, age for fish captured from four sites (Frankfort, MI; Manistique, MI; Saugatuck, MI; Waukegan, IL) were determined using scales. Between 1973 and 1982, scales were removed from a random selection of bloaters at each site, whereas after 1982, scales were removed from the first 10 fish encountered from each 10-mm-length class. Age was estimated counting the number of annuli on a projected scale image. Bloater ages ranged from 0 to 13 years, but we assume that scales provide an unbiased age estimate only up to age 6 (Bunnell et al. 2012a). Abundance of age-3 bloater was used as an index of recruitment because interpretation of catch curves revealed that individuals do not fully recruit to the bottom trawl until that age (Bunnell et al. 2006). Even though age-3 abundance is relatively late to assess year-class strength, abundance of age-0 bloater in Lake Michigan was positively related ( $r=0.68$; Bunnell et al. 2010) to the number of age- 3 bloater sampled three years later.

To estimate the abundance of age-3 bloater in a given year, we developed 'keys' that assigned probabilistic distributions of fish age and sex for each 10mm-length bin (for details see Bunnell et al. 2006). To calculate 'lakewide' abundance for each age class (including those older than 6 years), we first calculated the average numeric density (number of fish per ha) for each depth stratum, multiplied by the representative surface area, and summed across depth strata (which included depths from 5 to $114 \mathrm{~m}$ ).

To estimate the mean 'lakewide' biomass $\left(\mathrm{kg} \cdot \mathrm{ha}^{-1}\right)$ of slimy and deepwater sculpins, we used a similar approach to bloater, in that, we first calculated the average density $\left(\mathrm{kg} \cdot \mathrm{ha}^{-1}\right)$ for each depth stratum. We then calculated the weighted average biomass across depth strata, where the surface area of each depth stratum was the weighting factor. Finally, we plotted density of age-3 bloater recruits as a function of slimy or deepwater sculpin biomass density three years earlier, when the eggs were incubating for that particular year-class. Given the pattern in the scatterplot, we fit an exponential decay function $\left(y=\mathrm{ae}^{-b x}\right)$ using nonlinear regression, where $y$ equals bloater recruitment and $x$ equals sculpin biomass.

Evaluating egg predation mechanism through simulation modelling

To estimate bloater egg production in each year, we calculated mean size and abundance of females in all 
age classes. We assumed that abundance and size distribution of bloaters in autumn were unchanged by the time spawning began 4 months later. For each age class, we multiplied the proportion of females that were mature (estimated in Bunnell et al. 2012a) by the numeric abundance and applied one fecundity versus weight relationship (using average weight per year) between 1973 and 1983 (when bloater condition was high) and another relationship between 1984 and 2009 (when bloater condition was low, Bunnell et al. 2009). Population egg production equalled the sum of eggs produced across age classes.

We generated a lakewide bloater egg consumption estimate for both slimy and deepwater sculpin during 2009 using two methods. The first method used an individual-based modelling (IBM) approach to incorporate empirically based variability in the sizes, diet proportions and daily rations of each sculpin species. Alternatively, the second method modelled the consumption of an average individual. We found that these two different estimates produced nearly identical results (Appendix S1); hence, we used the second (simpler) method to estimate lakewide bloater egg consumption between 1973 and 2010 and provide those details below.

Consumption of bloater eggs by an average individual sculpin was dependent upon a series of equations (Fig. 1, Table 2). First, the average size for each sculpin species was calculated using data from the USGS bottom trawl survey. Specifically, for each species, we calculated the mean TL among those individuals that were larger than the minimum size

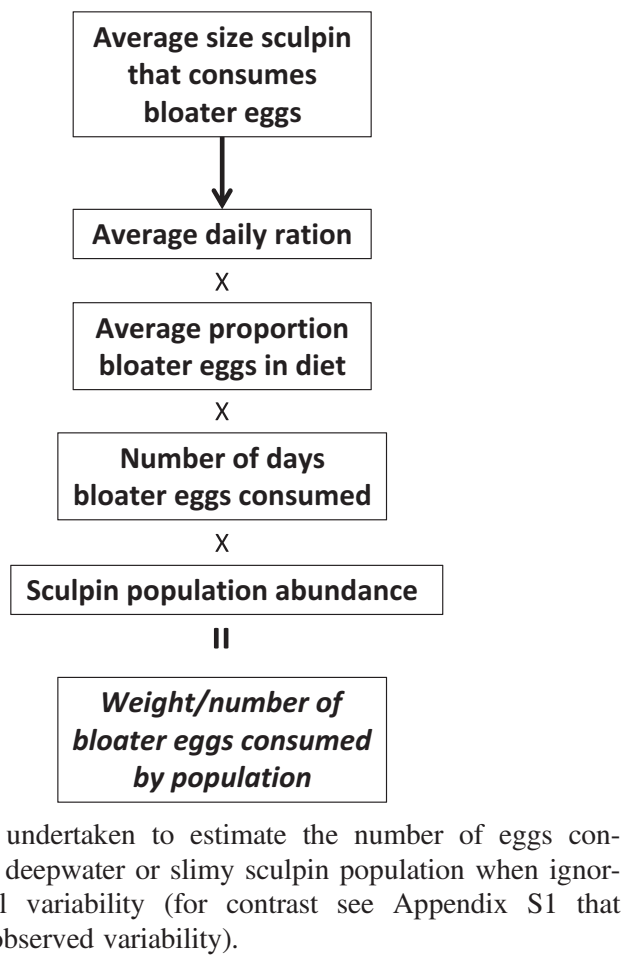
sumed by the deepwater or slimy sculpin population when ignoring individual variability (for contrast see Appendix S1 that incorporated observed variability). that consumed bloater eggs in 2009-2010: $\geq 40 \mathrm{~mm}$ TL for slimy sculpins and $\geq 91 \mathrm{~mm}$ TL for deepwater sculpins. Sculpin lengths were not regularly measured in the survey prior to 1999 . Therefore, we applied the mean TL of slimy sculpins between 1999 and 2012 $(68.9 \mathrm{~mm}$, which did not vary across those years: $F_{1,12}=1.6 ; P=0.23$ ) to earlier years. For deepwater sculpin, mean TL declined annually between 1999 and $2012\left(F_{1,12}=12.2 ; P=0.005\right)$, which led us to apply the mean TL of deepwater sculpins between 1999 and $2002(118.8 \mathrm{~mm})$ to earlier years.

The index of fullness ( $\mathrm{g}$ dry prey consumed per $\mathrm{g}$ dry fish) was estimated as a function of the mean weight (Table 2) of sculpin in each year. Predicted daily ration (g dry prey consumed) was then estimated by multiplying index of fullness by 24 and the laboratory-based gastric evacuation rates (Mychek-Londer \& Bunnell 2013) developed for each species (Table 2). The proportion of the diet that included bloater eggs was based on field-collected samples of sculpin, where eggs in the diets were assigned to species through genetic techniques (Mychek-Londer et al. 2013). Bloater eggs occurred in $11 \%$ of both slimy $(N=1016)$ and deepwater sculpin $(N=735)$ diets in 2009-2010. To explore whether the presence of bloater eggs in the diet was influenced by day of the year, depth of capture or fish size, we used logistic regression. Details of these analyses can be found in Appendix S2, and the results led us to ignore these effects. As a result, we multiplied the mean proportion of bloater eggs in the diet of each species by its daily ration and then divided by the dry/wet weight ratio of bloater eggs (Table 2) to estimate the wet weight of bloater eggs consumed by an average individual per day.

To extrapolate to the population, for each species, we multiplied the daily bloater egg consumption (by an average individual) by the lakewide abundance of those larger than the minimum size that consumed bloater eggs. To convert from daily to seasonal consumption for each species, we multiplied the average daily consumption by 90; pooling both 2009 and 2010 , diets were analysed at monthly intervals ranging between 12 January and 11 June for deepwater sculpins and between 12 January and 20 May for slimy sculpins, yet bloater eggs were found no earlier than 18 February and no later than 18 May, which spanned 90 days. To convert to the total number of bloater eggs consumed by sculpins in a given year, we divided the weight of bloater eggs by $0.004 \mathrm{~g}$ (the average wet weight of one bloater egg, J. Mychek-Londer, unpublished data).

\section{Results}

Using the long-term data set, recruitment of age-3 bloaters was inversely related to the biomass of slimy 


\section{Bunnell et al.}

Table 2. Equations and constants used to predict consumption of bloater eggs by slimy and deepwater sculpin in Lake Michigan between 1973 and 2010 (for further details see Mychek-Londer \& Bunnell 2013).

\begin{tabular}{lll}
\hline & Slimy sculpin & Deepwater sculpin \\
\hline Wet weight (WW, in grams) to total length (TL, in mm) regression & $\mathrm{WW}=3.195^{-6} \mathrm{TL}^{3.330}$ & $\mathrm{WW}^{2}=3.627^{-6} \mathrm{TL}^{3.210}$ \\
Daily ration ( $\mathrm{g}$ dry weight prey per day) & $\frac{1.60 \mathrm{DW}^{-0.47}}{100} \times 24 \times 0.0115 \times \mathrm{DW}$ & $\frac{1.58 \mathrm{DW}^{-0.55}}{100} \times 24 \times 0.0147 \times \mathrm{DW}$ \\
Dry weight (DW)/WW ratios & 0.216 & 0.209 \\
Mean proportion (dry weight) of bloater eggs in diet & 0.034 & 0.017 \\
Smallest size (TL) in which bloater eggs were found in the diet & 40 & 91 \\
Range of dates over which bloater eggs were found in the diet & 18 February-18 May & 18 February-18 May \\
\hline
\end{tabular}
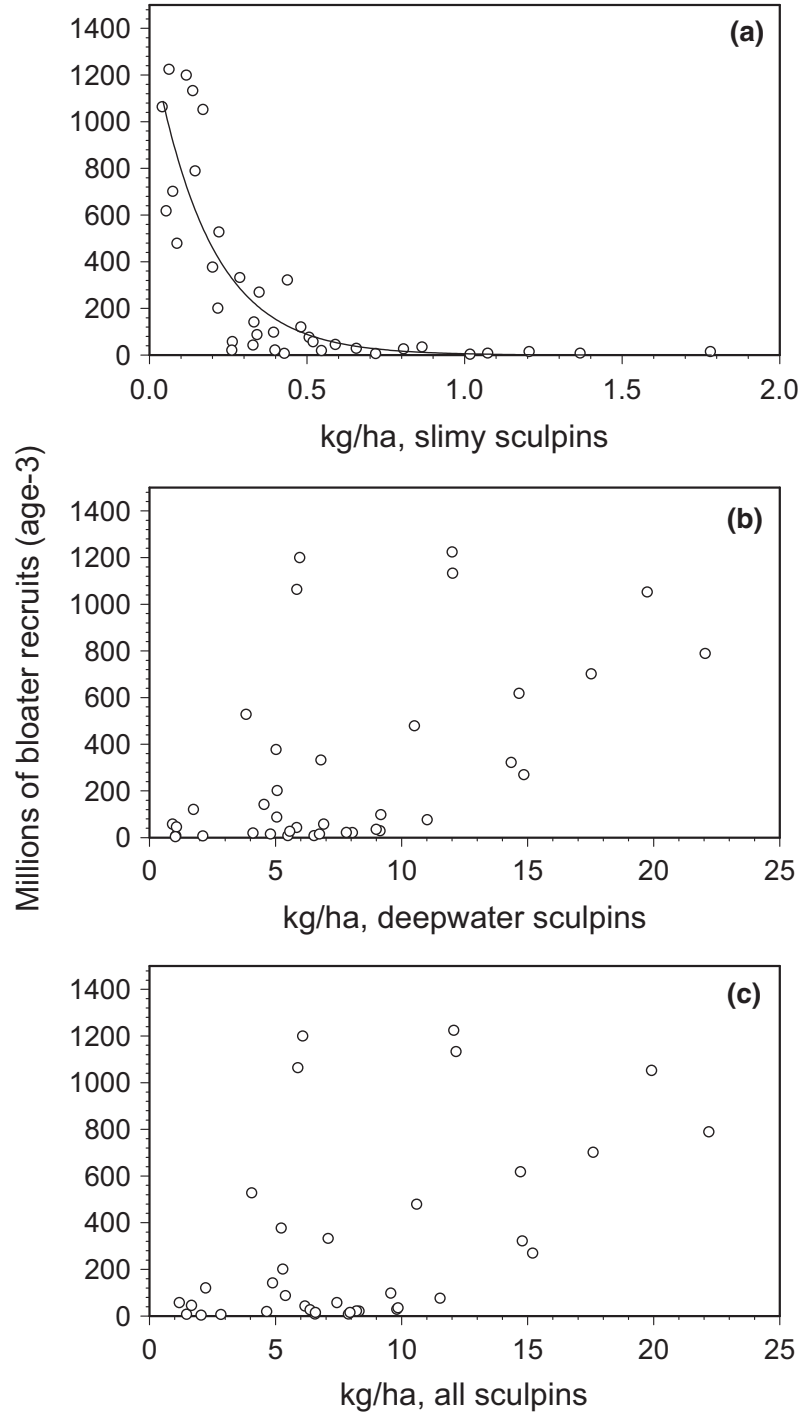

Fig. 2. Bloater recruitment (indexed at age 3) in Lake Michigan for the 1973 through 2009 year-classes as a function of the biomass of (a) slimy sculpin, (b) deepwater sculpin and (c) deepwater and slimy sculpins.

sculpin (Fig. 2a; $y=1375 e^{-5.479 X}, \quad F_{1,35}=91.8$, $\left.r^{2}=0.72 ; P<0.0001\right)$, but not deepwater sculpin (Fig. $2 \mathrm{~b} ; F_{1,35}=0.0 ; P=1.00$ ) that was estimated during the time of bloater egg incubation. When scul-

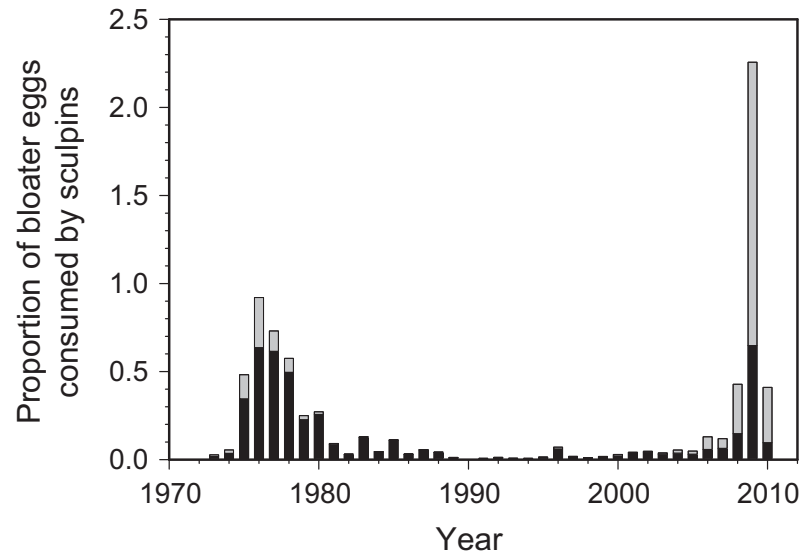

Fig. 3. Proportion of the annual bloater population egg production consumed by deepwater (black bar) and slimy (grey bar) sculpins between 1973 and 2010. Note that the y-axis exceeds 1.0 because egg consumption by sculpins was predicted to exceed bloater egg production in 2009.

pin biomass was combined, no relationship was apparent (Fig. 2c, $\mathrm{F}_{1,35}=0.0 ; \quad P=1.00$ ), likely because deepwater sculpin biomass was, on average, 43 times greater than that of slimy sculpin between 1973 and 2010.

Between 1973 and 2005, deepwater sculpins were always predicted to consume more bloater eggs than slimy sculpins (Fig. 3). Between 2006 and 2010, however, the pattern was reversed in every year except 2007. In general, only years early (19751980) and late (2008-2010) in the time series did the combined consumption by sculpins comprise a substantial $(\geq 0.25)$ proportion of egg production. Only in 2009 did the estimated consumption of eggs exceed the estimated bloater egg production, and in this year, consumption was estimated to be 2.3 times greater than bloater egg production.

Despite the occurrence of substantial consumption in some years, the correlative relationship identified from field sampling was not reproduced when the mechanistic modelling results were applied. For slimy sculpins (Fig. 4a), bloater recruitment was highly variable when the proportion of bloater eggs consumed was extremely low (i.e., $<0.03$ ), and then, 


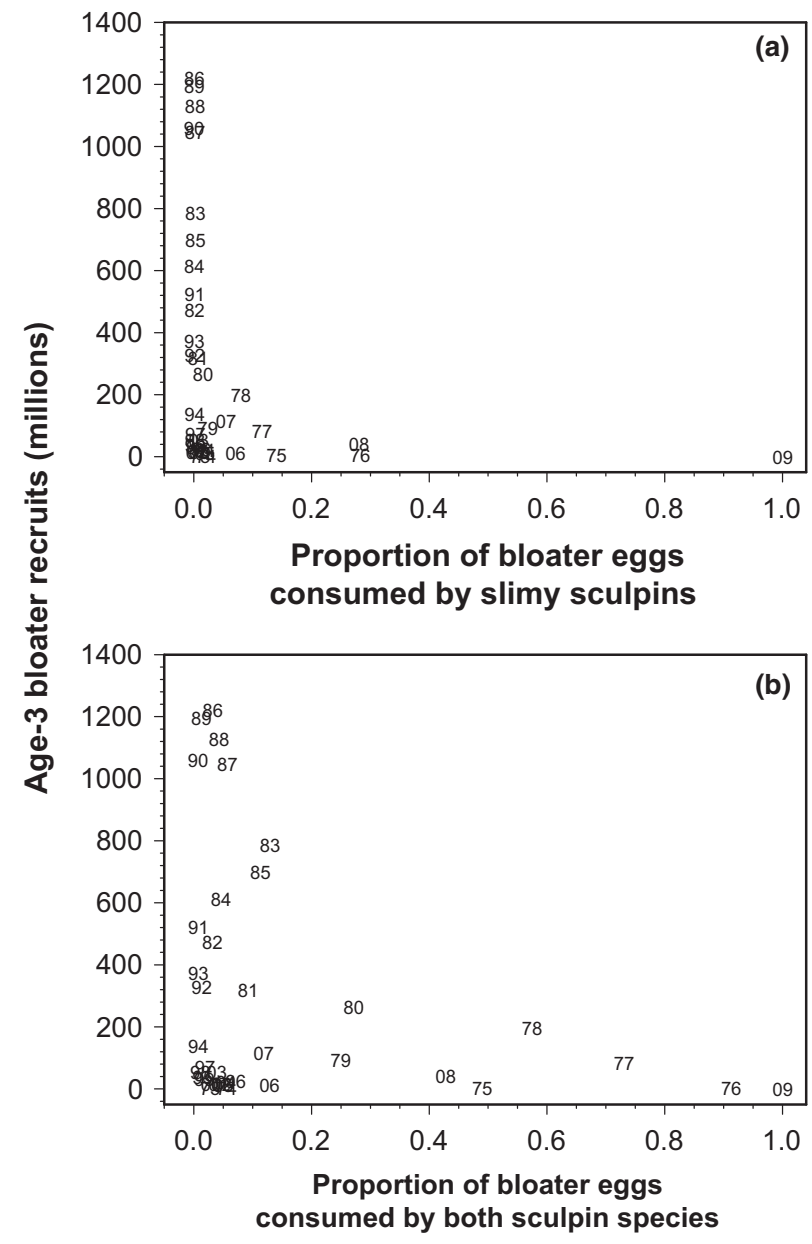

Fig. 4. Bloater recruitment (indexed at age 3) in Lake Michigan for the 1973 through 2009 year-classes as a function of the proportion of bloater eggs consumed by (a) slimy sculpin and (b) deepwater and slimy sculpins during the first year of life. The symbols represent the last two digits of the year-class (i.e., 1978 year-class equals 78). Note that the proportion in 2009 was set to 1.0 , despite the model estimating the value to be 1.61 in panel (a) and 2.26 in panel (b).

as the proportion increased above 0.10 , bloater recruitment remained consistently low. In comparison with Fig. 2a, bloater recruitment in Fig. 4a did not exhibit a consistent non-linear decline as the proportion of bloater eggs consumed by slimy sculpin increased. When egg predation by both the sculpin species was pooled (Fig. 4b), once again high recruitment variability occurred when the proportion of bloater eggs consumed was low, and consistently, low recruitment occurred as the proportions of egg consumed exceeded 0.2 .

\section{Discussion}

Despite a strong field pattern suggesting bloater recruitment was regulated by slimy sculpin biomass, models of predicted egg consumption by slimy (and deepwater) sculpin failed to support the hypothesis that egg predation was the singular factor regulating bloater recruitment in Lake Michigan. Consistent with the egg predation mechanism, several strong year-classes were produced in the late 1980s when the proportion of eggs consumed was low. Also consistent with the mechanism, when the proportion of bloater eggs consumed by slimy sculpins was at its highest (i.e., $\geq 0.10$ ), bloater recruitment was relatively weak. Inconsistent with this mechanism, however, was a cluster of year-classes including 19952005 when bloater produced extremely weak yearclasses despite very low (i.e., <0.02) proportions of bloater eggs being consumed by slimy sculpins. These relationships were not markedly different when consumption by deepwater and slimy sculpin was pooled. Although our models provided strong evidence that egg predation by sculpins can be sufficiently large to limit bloater recruitment, they also indicated that some other factor must have been limiting bloater recruitment between 1995 and 2005 when the proportion of eggs consumed was relatively low.

Our proportions of bloater egg production consumed by sculpins should not be viewed as absolute estimates for several reasons. First, there are multiple sources of uncertainty for both sculpin consumption and bloater egg production, yet a conventional sensitivity analysis was not completed because these estimates are the multiplicative product of several variables and, as such, increasing one of the variables by $\pm 10 \%$ would have directly increased consumption by $\pm 10 \%$. As a result, we discuss which variables had the greatest uncertainty in their estimates. First, our estimates of bloater and sculpin abundance were generated from bottom trawl surveys that sampled soft substrates (i.e., sand) at depths no greater than $110 \mathrm{~m}$ and resulted in relative standard errors $[\mathrm{RSE}=($ standard error/mean $) \times 100 \%]$ that averaged $21 \%$ for bloater, $23 \%$ for deepwater sculpin and $38 \%$ for slimy sculpin between 1973 and 2010. Given that our surveys aim for RSE $\leq 30 \%$ (Walters $\&$ Ludwig 1981), our uncertainty appeared reasonable for bloater and deepwater sculpin, but somewhat high for slimy sculpin. Furthermore, each species has been occurring at increasingly greater depths over the past decade (Madenjian \& Bunnell 2008; Bunnell et al. 2012b), and portions of each population likely reside at depths greater than those sampled by the survey (i.e., $110 \mathrm{~m}$ ). Second, sculpins likely attain higher densities on hard substrates, given that Houghton et al. (2010) reported slimy sculpin densities on offshore, rocky reefs in Lake Michigan that were two orders of magnitude higher than the highest annual estimate in our survey. Finally, bottom trawl sampling during the day does not capture $100 \%$ of bloaters or sculpins in its path, owing either to gear avoidance or behaviours that cause fish to either be 
burrowed in the substrate below where the net passes or above the height of the net. Comparisons between day and night bottom trawls in lakes Michigan and Superior have revealed that night-time estimates for slimy and deepwater sculpin abundances are at least five times greater than daytime ones (Brandt et al. 1980; Yule et al. 2008). In contrast, daytime estimates for bloater abundance were not different from those that summed estimates from night bottom trawls and acoustics with mid-water trawls (Yule et al. 2007).

Sources of variation beyond sculpin abundance influenced our consumption estimate. For example, the number of days over which we assumed sculpins were consuming bloater eggs was constrained by our sampling, which was approximately monthly. More frequent sampling may have improved the accuracy of this estimate. Additionally, we assumed that diets of sculpins in 2009-2010 could be applied back to 1973. Although no previous studies identified fish eggs to species, coarse comparisons can be made between proportion of all fish eggs in the diet in 2009-2010 (January-May, Mychek-Londer et al. 2013) and in the 1960s and 1970s (March-November, Wells 1980) at comparable depths. For slimy sculpins, the proportion of all fish eggs was comparable (0.04 in 1965-1966; 0.06 in 2009-2010), although the per cent occurrence declined between 1965 and 1966 (27\%) and 2009 and 2010 (14\%). For deepwater sculpins, the proportion of all fish eggs was over three times higher in 2009-2010 (0.07) than in 1965-1966 and 1974-1975 (0.02), and the per cent occurrence was also higher in the latter years $(25 \%$ vs. $14 \%)$. Hence, we can speculate that applying the 2009-2010 diet proportions to earlier years seemed reasonable for slimy sculpins but may have overestimated the importance of bloater eggs for deepwater sculpins prior to 2009.

We acknowledge that our estimate of egg consumption did not include other possible egg predators, including bloater, round goby and invertebrates such as Mysis spp. and crayfish. Although Wells \& Beeton (1963) reported a relatively high per cent occurrence of fish eggs from Lake Michigan bloater diets in April 1962 (30\% in depths 49-77 m, 56\% in depths 78-110 m), we quantified the diets of 294 Lake Michigan bloater from January through May, 2009-2010 (at the same offshore depths where sculpins were sampled) and found only 1 individual that consumed fish eggs ( $0.3 \%$ occurrence); 10 of 180 eggs in that diet were randomly sampled for genetic analysis and, all were determined to be bloater (W. Stott, Michigan State University, personal communication). Similarly, diets from 552 round gobies sampled during winter and spring, 2009-2010 (at the same depths as sculpins and bloaters) revealed only rare $(1 \%)$ occurrence of fish egg consumption
(Mychek-Londer et al. 2013). Examination of Mysis diets has revealed their capability to eat prey far larger than bloater eggs, yet no fish eggs have ever been found in their diets (e.g., Johannsson et al. 2001; Nordin et al. 2008). Finally, although crayfish can be effective egg predators in the Great Lakes (Fitzsimons et al. 2002), they likely do not occur at depths where bloater spawn. Thus, our focus on slimy and deepwater sculpin likely included the most important egg predators in offshore Lake Michigan.

Given these above caveats, how might future research improve our understanding of the relationship between sculpin predation and bloater recruitment? First, researchers should seek to reduce the uncertainty surrounding the abundance estimates for bloater and sculpin through expanding sampling efforts to include greater depths, hard substrates (i.e., offshore rocky reefs), and comparing day versus night density estimates. Second, researchers need to identify preferred bloater-spawning habitat. For example, if bloater preferentially spawn on offshore reefs or seek abrupt changes in bathymetry, that would further prioritize the need to estimate densities of sculpin egg predators in those habitats. Third, improved knowledge regarding bloater-spawning behaviour could reveal why male bloater die at a higher rate than females (see Bunnell et al. 2012a) or why bloater eggs appear less vulnerable to predation by an individual sculpin than deepwater sculpin eggs (i.e., for a given individual sculpin, the maximum number of eggs found in any one stomach was only 14 for bloater eggs but 90 for deepwater sculpin eggs, Mychek-Londer et al. 2013).

Although many caveats to our estimates can be raised, previous research in freshwater ecosystems has reported similarly high proportions of population egg production being consumed. For example, Jones et al. (1995) modelled the proportion of lake trout eggs (and fry) consumed under different scenarios of predation and reported values ranging 0.47-1.00. Empirical studies that have tracked the fate of incubating fish eggs have found that as many as 79-99\% of eggs will succumb to some source of mortality before hatching (Johnson 1961; Rupp 1965; Fitzsimons 1995; Perkins \& Krueger 1995), and threats beyond predation can be prevalent. For example, benthic eggs can be subjected to disturbance by winddriven currents that may cause them to be buried under shifting sediments (Fitzsimons 1995; Perkins \& Krueger 1995; Fitzsimons et al. 2007), and cool water temperatures can extend incubation and possibly increase the risk of mortality (e.g., Rice et al. 1987b). In the hypolimnetic waters of Lake Michigan where bloater eggs are incubating and temperatures are relatively stable yet cold, we suspect that predation would be the primary source of egg mortality, 
although disturbance by currents remains a possibility (Gottlieb et al. 1989). Temperature likely has no direct effect on bloater egg survival given that Rice et al. (1987b) reported normative survival at $2{ }^{\circ} \mathrm{C}$.

Our work contributes to the body of knowledge that seeks to determine the population-level impact of egg predation relative to other key drivers of fish recruitment. For example, a model that included Atlantic herring Clupea harengus biomass (which are known to prey on eggs and larvae) and the abundance of copepod prey best explained variation in the recruitment of Atlantic cod Gadus morhua in the North Sea over a 44-year time series (Fauchald 2010). Similarly, the population dynamics of Atlantic herring in Georges Bank were explained by a model that included egg predation by haddock Melanogrammus aeglefinus and fishing mortality (Richardson et al. 2011) and an approach similar to ours that coupled empirical diet information, daily ration, and population modelling revealed substantial egg predation by two clupeid species on Baltic cod eggs (Köster \& Möllmann 2000). In freshwater ecosystems, predation on eggs, but not larvae, likely regulated recruitment of lake sturgeon Acipenser fulvescens in the Peshtigo River (a tributary to Lake Michigan in Wisconsin, United States, Caroffino et al. 2010) and the abundance of invasive common carp Cyprinus carpio in a series of interconnected lakes in the Upper Mississippi River basin (Bajer et al. 2012). These population-level studies that have revealed the importance of egg predators are also bolstered by experimental work that has revealed that predation by fish or invertebrates to be the most important driver of the number of eggs that ultimately are hatched (e.g., Bouwes \& Luecke 1997; Steinhart et al. 2004; Etheridge et al. 2011; Setzer et al. 2011).

In our study, egg predation by sculpins could not singularly explain the recruitment variability exhibited by the 1973-2009 bloater year-classes. At the same time, our results provided an evidence that egg predation regulates bloater recruitment during some periods within the long time series and found that consumption could even exceed bloater egg production in 2009, when slimy sculpin were near record high levels of abundance (Bunnell et al. 2013). Hence, should recruitment by bloater continue to be weak in the 2010 and later year-classes and slimy sculpin densities remain at above-average levels (although they have declined since 2009, Bunnell et al. 2013), we argue that egg consumption by native benthivores could be an important contributor to poor bloater recruitment. In addition, future research will be required to explore what might have limited bloater recruitment during 1995-2005 when predation by sculpins was extremely low. Of the factors listed in Table 1, female predominance was relatively unique over this period as females ranged $73-86 \%$ of the adult population. Hence, future simulation models could explore how skewed sex ratios or some other factor intrinsic to the bloater population could cause bloaters to cycle in abundance (see Madenjian et al. 2002).

The recently high levels of slimy sculpin biomass in Lake Michigan, coupled with our modelling results predicting their potential negative impact on bloater recruitment, demonstrate the importance of considering a broader ecosystem perspective when considering management approaches to restore bloater populations. In particular, given previous knowledge demonstrating the top-down effects of piscivorous juvenile lake trout on slimy sculpin (Madenjian et al. 2005), one could hypothesise that if juvenile lake trout had attained higher densities since 2005, then slimy sculpin densities would have been reduced to a level that would have increased bloater egg survival and recruitment. Interestingly, managers in Lake Michigan recently developed a new strategy to rehabilitate lake trout populations (Bronte et al. 2008), and our findings could provide additional justification for those efforts.

Beyond bloater population dynamics in Lake Michigan, the synchrony that was observed among bloater populations in lakes Michigan, Huron and Superior between 1978 and 2006 (Bunnell et al. 2010) appears to have weakened, based on recent bottom trawl surveys. Age-0 bloater density measured by the USGS Lake Huron bottom trawl survey was markedly higher between 2005 and 2009 relative to the 1990s (Roseman et al. 2013), and comparable surveys in Lakes Michigan (Bunnell et al. 2013) and Superior (Gorman et al. 2013) detected no similar increase. The recent strong recruitment in Lake Huron led to a record high estimate of adult bloater abundance in 2012 (since the survey began in 1976). Why increased recruitment was detected in Lake Huron but not in the other two lakes is unknown. Given our modelling results and the observation that mean biomass of slimy and deepwater sculpins in Lake Huron between 2005 and 2009 were only 0.1 and $13.4 \%$ respectively, of the mean biomass in Lake Michigan (S.R. Riley, USGS, unpublished data), future research should explore whether the recovery of bloater in Lake Huron was a function of relatively low egg predation. Beyond these three lakes, yearling bloaters were stocked in Lake Ontario in 2012 to reestablish an endemic prey fish, and further stocking is planned for future years. We believe that improved understanding of the primary bottleneck to bloater recruitment in Lakes Michigan, Huron or Superior should ultimately be of use to managers in Lake Ontario so that the probability of building naturalised and sustainable populations can be maximised. For 


\section{Bunnell et al.}

example, if egg predation is, in fact, identified as one of the key bottlenecks, then managers would want to continue stocking bloaters as yearlings and to consider densities of sculpin egg predators when estimating the spawning stock biomass required to produce measurable levels of wild bloater recruits.

\section{Acknowledgements}

Funding was provided by the Great Lakes Fishery Commission and their 'Re-establishment of Native Deepwater Fishes' theme area. This manuscript was improved by helpful comments from Andrew Muir, John Janssen and two anonymous reviewers. We thank Wendylee Stott for the genetic analyses of eggs found in the bloater diet. We thank Patty Armenio, Vincent Belill, Margret Chriscinske, Bruce Davis, Jim Diana, John French III, Greg Jacobs, Kevin Keeler, Melissa Kostich, Lynn Ogilvie, Mark Rogers, Wendylee Stott and Nicole Watson for their important technical and intellectual contributions. Any use of trade, product or firm names is for descriptive purposes only and does not imply endorsement by the U.S. Government. This article is Contribution 1793 of the U.S. Geological Survey Great Lakes Science Center.

\section{References}

Auer, N.A. 1982. Family Salmonidae. In: Auer, N.A., ed. Identification of larval fishes of the Great Lakes basin with emphasis on the Lake Michigan drainage. Ann Arbor, MI: Great Lakes Fishery Commission Special Publication 82-3, pp. 80-145.

Bajer, P.G., Chizinski, C.J., Silbernagel, J.J. \& Sorensen, P.W. 2012. Variation in native micro-predator abundance explains recruitment of a mobile invasive fish, the common carp, in a naturally unstable environment. Biological Invasions 14: 1919-1929.

Barbiero, R.P. \& Tuchman, M.L. 2004. Changes in the crustacean communities of Lakes Michigan, Huron, and Erie following the invasion of the predatory cladoceran Bythotrephes longimanus. Canadian Journal of Fisheries and Aquatic Sciences 61: 2111-2125.

Barbiero, R.P., Lesht, B.M. \& Warren, G.J. 2012. Convergence of trophic state and the lower food web in Lakes Huron, Michigan, and Superior. Journal of Great Lakes Research 38: 368-380.

Bouwes, N. \& Luecke, C. 1997. The fate of Bonneville cisco eggs in Bear Lake: evaluating mechanisms of egg loss. Transactions of the American Fisheries Society 126: 240-247.

Brandt, S.B., Magnuson, J.J. \& Crowder, L.B. 1980. Thermal habitat partitioning by fishes in Lake Michigan. Canadian Journal of Fisheries and Aquatic Sciences 37: 1557-1564.

Bronte, C.R., Krueger, C.C., Holey, M.E., Toneys, M.L., Eshenroder, R.L. \& Jonas, J.L. 2008. A guide for the rehabilitation of lake trout in Lake Michigan. Great Lakes Fishery Commission Miscellaneous Publication 2008-01. Available at: http://www.glfc.org/pubs/pub.htm\#misc. Last accessed August 2013.

Brown, E.H., Argyle, R.L., Payne, N.R. \& Holey, M.E. 1987. Yield and dynamics of destabilized chub (Coregonus spp.) populations in Lakes Michigan and Huron. Canadian Journal of Fisheries and Aquatic Sciences 44(Suppl. 2): 371-383.

Brown, R.W., Taylor, W.W. \& Assel, R.A. 1993. Factors affecting the recruitment of Lake Whitefish in two areas of northern Lake Michigan. Journal of Great Lakes Research 19: 418-428.

Bunnell, D.B., Madenjian, C.P. \& Croley, T.E. 2006. Longterm trends of bloater recruitment in Lake Michigan: evidence for the effect of sex ratio. Canadian Journal of Fisheries and Aquatic Sciences 63: 832-844.

Bunnell, D.B., David, S.R. \& Madenjian, C.P. 2009. Decline in bloater fecundity in southern Lake Michigan after decline of Diporeia. Journal of Great Lakes Research 35: 45-49.

Bunnell, D.B., Adams, J.V., Gorman, O.T., Madenjian, C.P., Riley, S.C., Roseman, E.F. \& Schaeffer, J.S. 2010. Population synchrony of a native fish across the upper Great Lakes: evaluating the effects of dispersal and climate. Oecologia 162: 641-651.

Bunnell, D.B., Madenjian, C.P., Rogers, M.W., Holuszko, J.D. \& Begnoche, L.J. 2012a. Exploring mechanisms underlying differences in sex-specific mortality rate in Lake Michigan bloater. Transactions of the American Fisheries Society 141: 204-214.

Bunnell, D.B., Eshenroder, R.L., Krause, A.E. \& Adams, J.V. 2012b. Depth segregation of deepwater ciscoes (Coregonus spp.) in Lake Michigan during 1930-1932 and range expansion of Coregonus hoyi into deeper waters after the 1990s. Advances in Limnology (Biology and Management of Coregonid Fishes - 2008) 63: 3-24.

Bunnell, D.B., Madenjian, C.P., Desorcie, T.J., Kostich, M.J., Smith, K.R. \& Adams, J.V. 2013. Status and trends of preyfish populations in Lake Michigan in 2012. Distributed at the Lake Michigan Committee meeting, March 2013. Available at: http://www.glsc.usgs.gov/_files/reports/2012LakeMichiganPreyfish.pdf. Last accessed August 2013.

Caroffino, D.C., Sutton, T.M., Elliott, R.F. \& Donofrio, M.C. 2010. Predation on early life stages of lake sturgeon in the Peshtigo River, Wisconsin. Transactions of the American Fisheries Society 139: 1846-1856.

Collingsworth, P.D., Bunnell, D.B., Madenjian, C.P. \& Riley, S.R. in press. Comparative population dynamics of alewife (Alosa pseudoharengus) and bloater (Coregonus hoyi) in Lakes Michigan and Huron. Transactions of the American Fisheries Society. DOI: 10.1080/00028487.2013.833986.

Crowder, L.B. \& Crawford, H.L. 1984. Ecological shifts in resource use by bloaters in Lake Michigan. Transactions of the American Fisheries Society 113: 694-700.

Cushing, D.H. 1968. Fisheries biology: a study in population dynamics. Madison: University of Wisconsin Press. xii + $200 \mathrm{pp}$.

Eck, G.W. \& Wells, L. 1987. Recent changes in Lake Michigan's fish community and their probable causes, with emphasis on the role of the alewife (Alosa pseudoharengus). Canadian Journal of Fisheries and Aquatic Sciences 44(Suppl. 2): 53-60.

Etheridge, E.C., Bean, C.W. \& Adams, C.E. 2011. An experimental approach to estimating vulnerability of European whitefish (Coregonus lavaretus) ova to predation by invasive ruffe (Gymnocephalus cernuus). Ecology of Freshwater Fish 20: 299-307. 
Fauchald, P. 2010. Predator-prey reversal: a possible mechanism for ecosystem hysteresis in the North Sea? Ecology 91: 2191-2197.

Fitzsimons, J.D. 1995. Assessment of lake trout spawning habitat and egg deposition and survival in Lake Ontario. Journal of Great Lakes Research 21(Suppl. 1): 337-347.

Fitzsimons, J.D., Perkins, D.L. \& Krueger, C.C. 2002. Sculpins and crayfish in lake trout spawning areas in Lake Ontario: estimates of abundance and egg predation on lake trout eggs. Journal of Great Lakes Research 28: 421-436.

Fitzsimons, J.D., Jonas, J.L., Claramunt, R.M., Williston, B., Williston, G., Marsden, J.E., Ellrott, B.J. \& Honeyfield, D.C. 2007. Influence of egg predation and physical disturbance on lake trout Salvelinus namaycush egg mortality and implications for life-history theory. Journal of Fish Biology 71: 1-16.

Fratt, T.W., Coble, D.W., Copes, F. \& Bruesewitz, R.E. 1997. Diet of burbot in Green Bay and western Lake Michigan with comparison to other waters. Journal of Great Lakes Research 23: 1-10.

Gorman, O.T., Evrard, L.M., Cholwek, G.A. \& Vinson, M.R. 2013. Status and trends in the fish community of Lake Superior, 2012. Distributed at the Lake Superior Committee meeting, March 2013. Available at: http://www.glsc.usgs. gov/_files/reports/2012LakeSuperiorPreyfish.pdf. Last accessed August 2013.

Gottlieb, E.S., Saylor, J.H. \& Miller, G.S. 1989. Currents and temperatures observed in Lake Michigan from June 1982 to July 1983. NOAA Technical Memorandum ERL-GLERL 74. Available at: http://www.glerl.noaa.gov/ftp/publications/ tech_reports/glerl-071/tm-071.pdf. Last accessed August 2013.

Hjort, J. 1914. Fluctuations in the great fisheries of northern Europe. Rapports et Procès- verbaux des Réunions, Conseil Permanent International pour 1'Exploration de la Mer 20: 1228.

Hoagman, W.J. 1974. Feeding by alewives (Alosa pseudo harengus) on larval lake whitefish (Coregonus clupeaformis) in the laboratory. Journal of the Fisheries Research Board of Canada 31: 229-230.

Houde, E.D. 1987. Fish early life dynamics and recruitment variability. American Fisheries Society Symposium 2: 17 29.

Houghton, C.J., Bronte, C.R., Paddock, R.W. \& Janssen, J. 2010. Evidence for allochthonous prey delivery to Lake Michigan's Mid-Lake Reef Complex: are deep reefs analogs to oceanic sea mounts? Journal of Great Lakes Research 36: 666-673.

Hurst, T.P. 2007. Causes and consequences of winter mortality in fishes. Journal of Fish Biology 71: 315-345.

Johannsson, O.E., Leggett, M.F., Rudstam, L.G., Servos, M.R., Mohammadian, M.A., Gal, G., Dermott, R.M. \& Hesslein, R.H. 2001. Diet of Mysis relicta in Lake Ontario as revealed by stable isotope and gut content analysis. Canadian Journal of Fisheries and Aquatic Sciences 58: 19751986.

Johnson, F.H. 1961. Walleye egg survival during incubation on several types of bottom in Lake Winnibigoshish, Minnesota, and connecting waters. Transactions of the American Fisheries Society 90: 312-322.
Jones, M.L., Eck, G.W., Evans, D.O., Fabrizio, M.C., Hoff, M.H., Hudson, P.L., Janssen, J., Jude, D., O’Gorman, R. \& Savino, J.F. 1995. Limitations to lake trout (Salvelinus namaycush) rehabilitation in the Great Lakes imposed by biotic interactions occurring at early life stages. Journal of Great Lakes Research 21(Suppl. 1): 505-517.

Köster, F.W. \& Möllmann, C. 2000. Trophodynamic control by clupeid predators on recruitment success in Baltic cod? ICES Journal of Marine Science 57: 310-323.

Krueger, C.C., Perkins, D.L., Mills, E.L. \& Marsden, J.E. 1995. Predation by alewives on lake trout fry in Lake Ontario: role of an exotic species in preventing restoration of a native species. Journal of Great Lakes Research 21(Suppl. 1): 458-469.

Leggett, W.C. \& DeBlois, E. 1994. Recruitment in marine fishes: is it regulated by starvation and predation in the egg and larval stages? Netherlands Journal of Sea Research 32: 119-134.

Leggett, W.C., Frank, K.T. \& Carscadden, J.E. 1984. Meteorological and hydrographic regulation of year-class strength in capelin (Mallotus villosus). Canadian Journal of Fisheries and Aquatic Sciences 41: 1193-1201.

Madenjian, C.P. \& Bunnell, D.B. 2008. Depth distribution dynamics of the sculpin community in Lake Michigan. Transactions of the American Fisheries Society 137: 1346-1357.

Madenjian, C.P., DeSorcie, T.J. \& Stedman, R.A. 1998. Ontogenetic and spatial patterns in diet and growth of lake trout in Lake Michigan. Transactions of the American Fisheries Society 127: 236-252.

Madenjian, C.P., Fahnenstiel, G.L., Johengen, T.H., Nalepa, T.F., Vanderploeg, H.A., Fleischer, G.W., Schneeberger, P.J., Benjamin, D.M., Smith, E.B., Bence, J.R., Rutherford, E.S., Lavis, D.S., Robertson, D.M., Jude, D.J. \& Ebener, M.P. 2002. Dynamics of the Lake Michigan food web, 1970-2000. Canadian Journal of Fisheries and Aquatic Sciences 59: 736-753.

Madenjian, C.P., Hondorp, D.W., Desorcie, T.J. \& Holuszko, J.D. 2005. Sculpin community dynamics in Lake Michigan. Journal of Great Lakes Research 31: 267-276.

Madenjian, C.P., O’Gorman, R., Bunnell, D.B., Argyle, R.L., Roseman, E.F., Warner, D.M., Stockwell, J.D. \& Stapanian, M.A. 2008. Adverse effects of alewife (Alosa pseudoharengus) on Great Lakes fish communities. North American Journal of Fisheries Management 28: 263-282.

Mason, D.M. \& Brandt, S.B. 1996. Effect of alewife predation on survival of larval yellow perch in an embayment of Lake Ontario. Canadian Journal of Fisheries and Aquatic Sciences 53: $1609-1617$.

Miller, T.J., Crowder, L.B., Rice, J.A. \& Marschall, E.A. 1988. Larval size and recruitment mechanisms in fishes: toward a conceptual framework. Canadian Journal of Fisheries and Aquatic Sciences 45: 1657-1670.

Mills, E.L., Forney, J.L. \& Wagner, K.J. (1987) Fish predation and its cascading effect on the Oneida Lake food chain. In: Kerfoot, W.C. \& Sih, A., eds. Predation: direct and indirect impacts on aquatic communities. Hanover, New Hampshire: University Press of New England, pp. 118-131.

Mychek-Londer, J.G. \& Bunnell, D.B. 2013. Gastric evacuation rate, index of fullness, and daily ration of slimy sculpin (Cottus cognatus) and deepwater sculpin (Myoxocephalus thompsonii). Journal of Great Lakes Research 39: 327-335. 


\section{Bunnell et al.}

Mychek-Londer, J.G., Bunnell, D.B., Stott, W., Diana, J.S., French, J.R.P. \& Chriscinske, M.A. 2013. Using diets to reveal overlap and egg predation among benthivorous fishes in Lake Michigan. Transactions of the American Fisheries Society 142: 492-504.

Myers, R.A. \& Barrowman, N.J. 1996. Is fish recruitment related to spawner abundance? Fishery Bulletin 94: 707-724.

Nordin, L.J., Arts, M.T., Johannsson, O.E. \& Taylor, W.D. 2008. An evaluation of the diet of Mysis relicta using gut contents and fatty acid profiles in lakes with and without the invader Bythotrephes longimanus (Onychopoda, Cercopagidae). Aquatic Ecology 42: 421-436.

Perkins, D.L. \& Krueger, C.C. 1995. Dynamics of reproduction by hatchery-origin lake trout (Salvelinus namaycush) at Stony Island Reef, Lake Ontario. Journal of Great Lakes Research 21(Suppl. 1): 400-417.

Rice, J.A., Crowder, L.B. \& Binkowski, F.P. 1987a. Evaluating potential sources of mortality for larval bloater (Coregonus hoyi): starvation and vulnerability to predation. Canadian Journal of Fisheries and Aquatic Sciences 44: 467-472.

Rice, J.A., Crowder, L.B. \& Holey, M.E. 1987b. Exploration of mechanisms regulating larval survival in Lake Michigan bloater: a recruitment analysis based on characteristics of individual larvae. Transactions of the American Fisheries Society 116: 703-718.

Richardson, D.E., Hare, J.A., Fogarty, M.J. \& Link, J.S. 2011. Role of egg predation by haddock in the decline of an Atlantic herring population. Proceedings of the National Academy of Sciences 108: 13606-13611.

Riley, J.W. \& Marsden, J.E. 2009. Predation on emergent lake trout fry in Lake Champlain. Journal of Great Lakes Research 35: 175-181.

Roseman, E.F., Riley, S.C., Farha, S.A., Maitland, B.M., Tucker, T.R., Provo, S.A. \& McLean, M.W. 2013. Status and trends of the Lake Huron offshore demersal fish community, 1976-2012. Distributed at the Lake Huron Committee meeting, March 2013. Available at: http://www.glsc. usgs.gov/_files/reports/2012LakeHuronDemersal.pdf. Last accessed August 2013.

Rupp, R.S. 1965. Shore-spawning and survival of eggs of the American smelt. Transactions of the American Fisheries Society 94: 160-168.

Setzer, M., Norrgard, J.R. \& Jonsson, T. 2011. An invasive crayfish affects egg survival and the potential recovery of an endangered population of Arctic charr. Freshwater Biology 56: 2543-2553.

Stedman, R.M. \& Argyle, R.L. 1985. Rainbow smelt (Osmerus mordax) as predators on young bloaters (Coregonus hoyi) in Lake Michigan. Journal of Great Lakes Research 11: 4042.

Steinhart, G.B., Marschall, E.A. \& Stein, R.A. 2004. Round goby predation on smallmouth bass offspring in nests during simulated catch-and-release angling. Transactions of the American Fisheries Society 133: 121-131.

TeWinkel, L.M. \& Fleischer, G.W. 1999. Vertical migration and nighttime distribution of adult bloaters in Lake Michigan. Transactions of the American Fisheries Society 128: 459-474.

Walters, C.J. 1987. Nonstationarity of production relationships in exploited populations. Canadian Journal of Fisheries and Aquatic Sciences 44(Suppl. 2): 156-165.

Walters, C.J. \& Ludwig, D.L. 1981. Effects of measurement errors on the assessment of stock-recruitment relationships. Canadian Journal of Fisheries and Aquatic Sciences 38: 704-710.

Walters, C.J. \& Martell, S.J.D. 2004. Fisheries ecology and management. Princeton: Princeton University Press. xxi + 399 pp.

Wells, L. 1980. Food of alewives, yellow perch, spottail shiners, trout-perch, and slimy and fourhorn sculpins in southeastern Lake Michigan. US Fish and Wildlife Service Technical Paper 98.

Wells, L. \& Beeton, A.M. 1963. Food of the bloater, Coregonus hoyi, in Lake Michigan. Transactions of the American Fisheries Society 92: 245-255.

Yule, D.L., Adams, J.V., Stockwell, J.D. \& Gorman, O.T. 2007. Using multiple gears to assess acoustic detectability and biomass of fish species in Lake Superior. North American Journal of Fisheries Management 27: 106-126.

Yule, D.L., Adams, J.V., Stockwell, J.D. \& Gorman, O.T. 2008. Factors affecting bottom trawl catches: implications for monitoring the fishes of Lake Superior. North American Journal of Fisheries Management 28: 109-122.

\section{Supporting Information}

Additional Supporting Information may be found in the online version of this article:

Appendix S1. Estimating the consumption of bloater eggs by slimy and deepwater sculpins in 2009 with an individual-based modeling approach

Appendix S2. Exploring whether day of year, depth of capture, and size of sculpin influence explain variation in the proportion of bloater eggs observed in the diet 